\title{
Identification of Host Fruit Volatiles from Three Mayhaw Species (Crataegus Series Aestivales) Attractive to Mayhaw-Origin Rhagoletis pomonella Flies in the Southern United States
}

\author{
Dong H. Cha • Thomas H. Q. Powell • Jeffrey L. Feder • \\ Charles E. Linn Jr.
}

Received: 2 March 2011 /Revised: 13 August 2011 / Accepted: 19 August 2011 /Published online: 3 September 2011

(C) Springer Science+Business Media, LLC 2011

\begin{abstract}
The apple maggot fly, Rhagoletis pomonella, infests several hawthorn species in the southern USA. Here, we tested the hypothesis that these populations could serve as reservoirs for fruit odor discrimination behaviors facilitating sympatric host race formation and speciation, specifically the recent shift from downy hawthorn (Crataegus mollis) to domestic apple (Malus domestica) in the northern USA. Coupled gas chromatography and electroantennographic detection (GC-EAD), gas chromatography with mass spectrometry (GC-MS), and flight tunnel bioassays were used to identify the behaviorally active natal fruit volatile blends for three of the five major southern hawthorns: C. opaca (western mayhaw), C. aestivalis (eastern mayhaw), and $C$. rufula (a possible hybrid between $C$. opaca and $C$. aestivalis). A 6-component blend was developed for $C$. opaca (3-methylbutan-1-ol [44\%], pentyl acetate [6\%], butyl butanoate $[6 \%]$, propyl hexanoate $[6 \%]$, butyl hexanoate [26\%], and hexyl butanoate [12\%]); an 8-component blend for C. aestivalis (3-methylbutan-1-ol [2\%], butyl acetate [47\%], pentyl acetate [2\%], butyl butanoate [12\%], propyl hexanoate [1\%], butyl hexanoate [25\%], hexyl butanoate [9\%], and pentyl hexanoate [2\%]); and a 9-component blend for C. rufula (3-methylbutan-1-ol [1\%], butyl acetate [57\%], 3-methylbutyl acetate [3\%], butyl butanoate [5\%], propyl hexanoate $[1 \%]$, hexyl propionate $[1 \%]$, butyl hexanoate
\end{abstract}

D. H. Cha $\cdot$ C. E. Linn Jr. $(\bowtie)$

Department of Entomology,

NYS Agricultural Experiment Station, Cornell University,

Geneva, NY 14456, USA

e-mail: CEL1@cornell.edu

T. H. Q. Powell • J. L. Feder

Department of Biological Sciences, University of Notre Dame,

Notre Dame, IN 46656, USA
[23\%], hexyl butanoate [6\%], and pentyl hexanoate [3\%]). Crataegus aestivalis and C. opaca-origin flies showed significantly higher levels of upwind directed flight to their natal blend in flight tunnel assays compared to the non-natal blend and previously developed apple, northern downy hawthorn, and flowering dogwood blends. Eastern and western mayhaw flies also were tested to the $C$. rufula blend, with eastern flies displaying higher levels of upwind flight compared with the western flies, likely due to the presence of butyl acetate in the C. aestivalis and C. rufula blends, an agonist compound for eastern mayhaw-origin flies, but a behavioral antagonist for western flies. The results discount the possibility that the apple fly was "preassembled" and originated via a recent introduction of southern mayhaw flies predisposed to accepting apple. Instead, the findings are consistent with the possibility of southern mayhaw-infesting fly host races. However, mayhaw fruits do emit several volatiles found in apple. It is, therefore, possible that the ability of the fly to evolve a preference for apple volatiles, although not the entire blend, stemmed, in part, from standing variation related to the presence of these compounds in southern mayhaw fruit.

Key Words Apple maggot fly. Sympatric speciation . Host races · Southern hawthorns · Olfaction · Fruit odor discrimination $\cdot$ Flight tunnel

\section{Introduction}

The apple maggot, Rhagoletis pomonella Walsh (Diptera: Tephritidae) is a model system for sympatric speciation via host plant shifting for phytophagous insects (Feder, 1998; Funk et al., 2002; Smadja and Butlin, 2009). In particular, 
the recent shift of the fly from its native host downy hawthorn, Crataegus mollis Sheele (Rosales: Rosaceae), to introduced Eurasian apple, Malus domestica Mill. (Rosales: Rosaceae) in the northeast United States about 160 years ago is often cited as an example of sympatric host race formation in action in the face of gene flow (Bush, 1966, 1969; Berlocher et al., 1993; Berlocher and Feder, 2002; Coyne and Orr, 2004; Smadja and Butlin, 2009). Genetic analysis (Feder et al., 1988; McPheron et al., 1988; Michel et al., 2010) and field studies (Feder et al., 1993, 1994) have confirmed the status of apple and hawthorn flies as partially ecologically reproductively isolated host races, the hypothesized first stage in sympatric speciation. Significant allele frequency, but not fixed, genetic differences have been documented for a number of loci between the apple and hawthorn fly races (Michel et al., 2010). In addition, mark-release-recapture studies in the field have shown that host fidelity while strong, is not absolute, and currently inter-host migration between apples and hawthorns occurs at a rate of $\sim 4-6 \%$ per generation (Feder et al., 1994). Apple and hawthorn flies readily mate with each other in the lab and produce viable and fertile offspring (Dambroski et al., 2005). Consequently, there appears to be no obvious intrinsic post-zygotic reproductive isolation between the host races, and apple and hawthorn flies are primarily, if not exclusively, isolated by ecological barriers to gene flow.

Two host-related adaptations are important traits that facilitate the host shift of $R$. pomonella to apple and contributing to partial ecological reproductive isolation between the apple and hawthorn fly races. The first involves diapause life history adaptation matching the eclosion time of emerging adult flies to a difference in the fruiting times of apples vs. hawthorns (apple varieties favored by the fly generally bear fruit $\sim 3-4$ weeks earlier than hawthorns) (Bush, 1969; Feder et al., 1993, 1994). The difference in eclosion time generates allochronic mating isolation between the host races (Feder et al., 1993; Filchak et al., 2000). The second trait involves host-plant choice. Apple and hawthorn flies prefer to mate on or near the fruit of their respective host plants (Prokopy et al., 1971, 1972). Hence, differences in host plant choice translate directly to mate choice and generate premating reproductive isolation (Feder et al., 1994). One such difference involves volatile compounds emitted by ripening host fruit that are used to recognize and distinguish among alternative host plants (Linn et al., 2003; Forbes et al., 2005). Not only do apple and downy hawthorn flies preferentially orient to their respective natal fruit volatiles, but their upwind-directed flight also is antagonized (arrested) by non-natal volatiles (Forbes et al., 2005; Linn et al., 2005a). Antagonism is important because it indicates that when flies shift to a new host plant, not only do they rapidly evolve and positively behaviorally respond to the volatile profile of the new fruit (where offspring survivorship is higher) but also avoid certain volatiles of the ancestral host fruit (where fitness is lower).

Divergence along these two axes: eclosion phenology and host odor response, has led to considerable, but still incomplete reproductive isolation between races. Markrecapture studies estimate a migration rate of $\sim 4-6 \%$ at sympatric sites (Feder et al., 1994), more than enough to homogenize allele frequencies of the races in the absence of selection (Feder, 1998). While $F_{1}$ hybrids between races are intrinsically viable (Reissig and Smith, 1978), they are ecologically unfit due to life history tradeoffs (Filchak et al., 2000) and diminished olfactory response to either parental host fruit (Linn et al., 2004). Thus, genetic differences between races (Feder et al., 1988; McPheron et al., 1988; Michel et al., 2010) are actively maintained by divergent selection on these two key ecological traits.

In contrast to the northern USA, R. pomonella infests an array of different hawthorn species in the South (Note: domesticated apple does not thrive in the southern USA, and so the apple race is limited in its distribution to the Northeast, Midwest, and Appalachian Mountains). In this regard, it has been suggested that perhaps the apple race did not originate via a sympatric host shift from the endemic downy hawthorn in the Northeast but from migration of a geographically differentiated, hawthorn-infesting form of the fly from the South (Carson, 1989; although see Bush et al., 1989). This would imply that in the southern USA, a "pre-adapted" hawthorn-infesting population of $R$. pomonella exists that preferentially responds to apple fruit volatiles and is antagonized by downy hawthorn fruit volatiles. It also is possible, however, that $R$. pomonella has formed a series of sympatric host races on the various species of native hawthorn present in the South (Berlocher and Enquist, 1993). Indeed, the five major hawthorn hosts of $R$. pomonella in the South (western mayhaw, C. opaca; eastern mayhaw, C. aestivalis; blueberry hawthorn, $C$. brachyacantha; green hawthorn, C. viridis; and downy hawthorn, C. mollis) generally overlap in their geographic ranges, but differ in key traits such as fruiting time, host fruit color and size, and potentially fruit volatiles, thus presenting the opportunity for host-related divergence. In this case, the southern hawthorn races would represent an example of a natural sympatric radiation onto a suite of native host species, complimenting the documented historical shift of the fly onto domesticated apple in recent times.

To investigate the possibilities of preformed apple vs. native hawthorn host races in the South, we initiated studies of the fruit volatile profiles and behavioral responses of $R$. pomonella to the major hawthorn hosts in the southern USA. Here, we focus on three related Crataegus species in the series Aestivales collectively known under the common name of "mayhaw". Rhagoletis pomonella infests both a western (C. opaca) and eastern (C. aestivalis) distributed 
species of mayhaw in the South. The range of $C$. opaca extends from eastern Texas, through all of Louisiana to southwestern Mississippi, with a northern limit in extreme southern Arkansas (Fig. 1). Crataegus aestivalis is found from southern Alabama through southern Georgia and central Florida, as well as along the Atlantic coast to North Carolina. Both $C$. aestivalis and $C$. opaca are grown commercially in their respective regions; the fruit is used to make jelly, syrup, and wine. The two species have an early fruiting phenology (mid April to late May), large edible fruits, and a requirement for damp and often flooded soil. The mayhaws are distinguished morphologically by the eastern $C$. aestivalis in having more glabrous oblongovate leaves, as opposed to the more cuneate leaves of the western C. opaca (Sargent, 1933). The fruit of C. aestivalis is smaller and more oblong in shape than C. opaca, which has a more depressed, globose fruit. A third described species, C. rufula, occurs primarily at the intersection of the eastern and western species' ranges between the lower Pearl River and Pascagoula River drainages in Mississippi. It is intermediate between $C$. opaca and $C$. aestivalis in both fruit and leaf morphology, and may represent a hybrid species. Collection of ripe C. rufula fruit from four field sites in this region of Mississippi from 2008 to 2010 failed to yield any Rhagoletis infestation.

The distinctive early fruiting time of southern mayhaws makes them prime candidates for the source of a potential shift to apple in the North. To assess this possibility, we developed volatile blends for the three mayhaw species through a combination of gas chromatography/electroantennographic detection (GC-EAD) and gas chromatography/mass spectrometric (GC-MS) analysis of both solid phase microextraction (SPME) and adsorbent samples collected from fruit headspace. Behavioral flight tunnel assays also were conducted using the different adsorbent extracts, mayhaw blends, and our previously developed apple, downy hawthorn, and flowering dogwood (Cornus florida) blends to test for possible olfactory pre-adaptation of mayhaw flies to apple. We report results showing that while mayhaws share some fruit volatiles in common with apple, the fruit odor profiles also differ in several key volatiles. Moreover, while eastern and western mayhaw flies preferentially oriented to their respective natal mayhaw blends, they were less responsive to the apple and downy hawthorn blends. Our findings are, therefore, consistent with the possibility of southern USA hawthorn-infesting host races of $R$. pomonella.

\section{Methods and Materials}

Insects Flies were collected, from a total of four different mayhaw sites (Fig. 1; Table 1), as larvae in infested host fruit and reared to adulthood in the Notre Dame laboratory

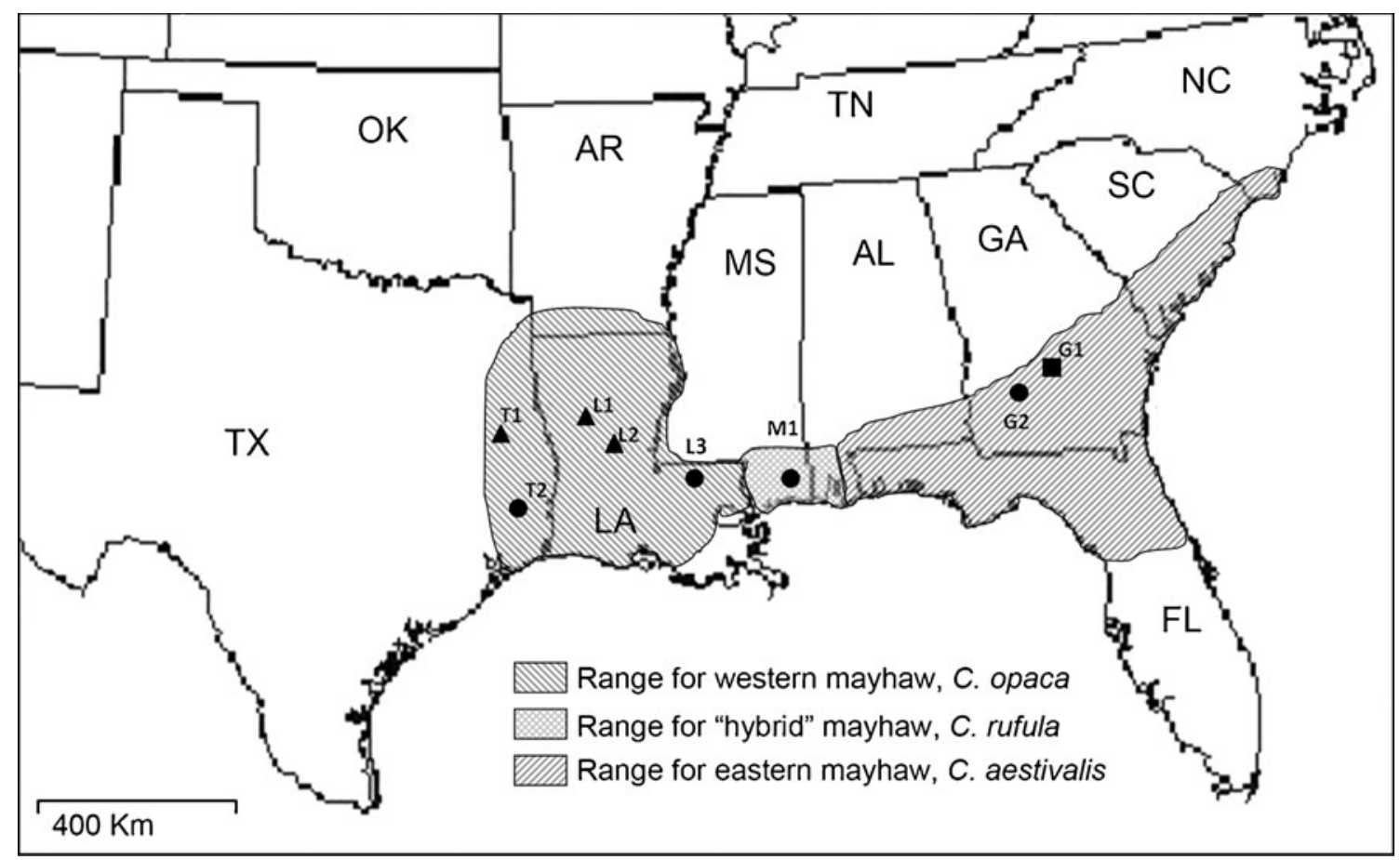

Fig. 1 Range map for western, Crataegus opaca, eastern, C. aestivalis, and "hybrid", C. rufula, mayhaws with collection sites for fruit (circles), flies (triangles), or both (squares). Abbreviations for each of the States indicated are: $A L$ Alabama, $A R$ Arkansas, $F L$ Florida, $G A$ Georgia, $L A$ Louisiana, $M S$ Mississippi, $N C$ North Carolina, $O K$ Oklahoma, $S C$ South Carolina, $T N$ Tennessee, $T X$ Texas 
Table 1 Collection sites for mayhaw fruits (Crataegus) and flies and their coordinates as marked in Fig. 1

\begin{tabular}{lllll}
\hline Map name & Host plant species & Location & Latitude & Longitude \\
\hline G1 & C. aestivalis & Byron USDA-ARS, Peach Co, GA & $32^{\circ} 39^{\prime} \mathrm{N}$ & $83^{\circ} 43^{\prime} \mathrm{W}$ \\
G2 & C. aestivalis & Arabi Warwick Rd, Crisp Co, GA & $31^{\circ} 50^{\prime} \mathrm{N}$ & $83^{\circ} 47^{\prime} \mathrm{W}$ \\
L1 & C. opaca & Lake Iatt, Grant Parish, LA & $31^{\circ} 38^{\prime} \mathrm{N}$ & $92^{\circ} 38^{\prime} \mathrm{W}$ \\
L2 & C. opaca & Dewey Wills WMA, La Salle Parish, LA & $31^{\circ} 27^{\prime} \mathrm{N}$ & $92^{\circ} 06^{\prime} \mathrm{W}$ \\
T1 & C. opaca & SFA exp. forest, Nacogdoches, Co, TX & $31^{\circ} 30^{\prime} \mathrm{N}$ & $94^{\circ} 46^{\prime} \mathrm{W}$ \\
T2 & C. opaca & HW Jackson Farm, Polk Co. TX & $30^{\circ} 31^{\prime} \mathrm{N}$ & $94^{\circ} 42^{\prime} \mathrm{W}$ \\
L3 & C. opaca & LSU Idlewild, East Feliciana Parish, LA & $30^{\circ} 49^{\prime} \mathrm{N}$ & $90^{\circ} 57^{\prime} \mathrm{W}$ \\
M1 & C. rufula & Parker Lake, Jackson Co. MS & $30^{\circ} 38^{\prime} \mathrm{N}$ & $88^{\circ} 35^{\prime} \mathrm{W}$ \\
\hline
\end{tabular}

using standard $R$. pomonella husbandry techniques (Neilson, 1965; Dambroski and Feder, 2007). Adult flies were shipped to the Cornell lab and kept in a walk-in environmental chamber at $23-24^{\circ} \mathrm{C}, 16 \mathrm{~L}: 8 \mathrm{D}$ photoperiod, and $65-70 \%$ r.h., on an artificial diet made of water, sugar, vitamins, casein hydrolysate, and salt mixture prior to testing (Fein et al., 1982). Adult flies at 0-7 and 10-21-d-old were used for GC-EAD analyses and flight-tunnel behavior tests, respectively. Younger flies were used for the GC-EAD analyses because they are more robust and stable in the EAD apparatus than older flies (Nojima et al., 2003a). In contrast, $R$. pomonella flies do not respond behaviorally to volatiles until they reach reproductive maturity at $>8 \mathrm{~d}$ post-eclosion (Fein et al., 1982).

Fruit Western mayhaw (C. opaca) fruit came from two locations: the Louisiana State University Idlewild Experimental Field Station, East Feliciana Parish, LA, USA, and the H.W. Jackson Farm, Polk Co., TX, USA (Fig. 1; Table 1). Eastern mayhaw (C. aestivalis) fruit also came from two sites: the USDA southern fruit and nut station, Byron, GA, USA, and Crisp Co., GA, USA (Fig. 1; Table 1). Fruit from the morphologically intermediate $C$. rufula were collected from Parker Lake in the Pascagoula Wildlife Management Area, Jackson Co., MS, USA (Fig. 1; Table 1). Fruit were collected from off of trees in the field and shipped overnight to the Cornell lab for volatile characterization. While it is possible that fruit on trees emit a different blend than newly picked fruit, this is an inherent methodological constraint of volatile collection. In this regard, we note three points. First, our goal was not to directly determine the exact volatile profile of fruit on trees, but rather to identify the key behaviorally active compounds inducing fly response, and to develop synthetic blends that elicit levels of orientation at least as high as whole fruit extracts. Candidate compounds were identified by GC-EAD analysis. Thus, while the composition of eluded compounds from newly picked fruit may differ from unpicked fruit on trees, the key volatiles for behavior should still be present and identified by GC-EAD. Second, previous studies have shown that Rhagoletis flies do not respond to all the volatiles emitted by fruit but a crucial subset of compounds (Zhang et al., 1999; Nojima et al., 2003a, b; Linn et al., 2003). Thus, determination of the exact composition of volatiles emitted by fruit on trees is not as important as identification of the subset of key compounds. Third, we eluted volatiles from activated charcoal adsorbent filters in collecting chambers every $24 \mathrm{~h}$ for a given fruit sample, and we combined the elution across 5 collecting days, as well as performing SPME sampling on the day following fruit collection. Thus, we sampled volatiles encompassing a period as close as we could following fruit collection in a manner to best ensure that all compounds were sampled in sufficient quantity to be detected by GC-EAD analysis.

Adsorbent Sampling Headspace volatiles were collected from whole fruit by using 2.41 closed volatile collection chambers (ARS, Inc., Gainesville, FL, USA; glass shop, Cornell University, Ithaca, NY, USA) with one air inlet adapter ( $7 \mathrm{~mm}$ ID) on the top and an outlet adapter ( $7 \mathrm{~mm}$ ID) on the bottom wall. Field collected fruit $(500-800 \mathrm{ml}$ in volume) were cleaned gently with distilled water, thoroughly dried, and then immediately put into a collection chamber. Clean air from a filtering and delivery system (ARS Inc., Gainesville, FL, USA) was pushed into the chamber at $0.7 \mathrm{~L}$ $\mathrm{min}^{-1}$ through the top inlet port, and volatiles from fruit were pushed out through volatile traps (activated charcoal adsorbent filters, ORBO32-small, Supelco Inc., Bellefonte, PA, USA) on the bottom of the chamber. An additional ORBO filter was used to ensure that no breakthrough occurred. For each sample of fruit, adsorbent collections were made over a $5 \mathrm{~d}$ period at room temperature using the same volatile trap. For each new fruit sample, the chambers were washed with acetone, purged with clean filtered air for $24 \mathrm{~h}$, and new ORBO filters were put in place. Volatiles were eluted with $500 \mu \mathrm{l}$ methylene chloride every $24 \mathrm{~h}$ from the filters of a given fruit sample and combined across the 5 collecting days. The combined extract was kept at $-20^{\circ} \mathrm{C}$ and subjected to GC-EAD, GC-MS, and flight tunnel analyses. 
SPME Sampling A glass jar $(500 \mathrm{ml})$ with Teflon liner screwcap (Wheaton, Milliville, NJ, USA), containing ca. $150 \mathrm{~g}$ of fruit, was used for SPME sampling. A carboxenpolydimethylsiloxane-coated SPME fiber (film thickness $85 \mu \mathrm{m}$, Supelco) was conditioned in the GC injector $\left(280^{\circ} \mathrm{C}\right)$ for $5 \mathrm{~min}$, and then passed through the small hole on the cap into the headspace of the jar. After a 10 to 20-min exposure, collected volatiles on the fiber were immediately subjected to GC-EAD analysis. The sampling container was washed with acetone before sampling new fruit.

Coupled Gas Chromatographic-Electroantennographic Detection (GC-EAD) Analysis Coupled GC-EAD analysis was performed as described previously (Zhang et al., 1999; Nojima et al., 2003a,b; Cha et al., 2008) using a Hewlett Packard 5890 Series II gas chromatograph equipped with a non-polar EC-1 capillary column $(30 \mathrm{~m} \times 0.25 \mathrm{~mm}$ ID, $0.25 \mu \mathrm{m}$ film thickness; Alltech Associates, Inc., Deerfield, IL, USA) or a Shimadzu GC-17A gas chromatograph equipped with a polar EC-Wax Econo-Cap capillary column (30 $\mathrm{m} \times 0.25 \mathrm{~mm}$ ID, $0.25 \mu \mathrm{m}$ film thickness; Alltech) in the splitless mode. The oven temperature was programmed at $40^{\circ} \mathrm{C}$ for $5 \mathrm{~min}$, then increased by $15^{\circ} \mathrm{C} / \mathrm{min}$ to $250^{\circ} \mathrm{C}$, and held for $5 \mathrm{~min}$. Injector and detector temperatures were set at $280^{\circ} \mathrm{C}$ and $270^{\circ} \mathrm{C}$, respectively. Nitrogen gas was the carrier at a flow of $2 \mathrm{ml} / \mathrm{min}$. The column effluent was split 1:1 in the oven via a "Y" glass splitter (Supelco). One arm of the splitter led to the flame ionization detector (FID) $\left(270^{\circ} \mathrm{C}\right)$ and the other to the heated EAD port $\left(270^{\circ} \mathrm{C}\right)$.

Whole head preparations were made of individual flies for GC-EAD analysis (Nojima et al., 2003a). The head was separated from the body and its antennae positioned between two gold wire electrodes immersed in salinefilled (Drosophila ringer solution; $46 \mathrm{mmol} \mathrm{NaCl}, 182 \mathrm{mmol}$ $\mathrm{KCl}, 3 \mathrm{mmol} \mathrm{CaCl}_{2}$, and $10 \mathrm{mmol}$ Tris $\mathrm{HCl}$ at $\mathrm{pH} 7.2$ ) micropipettes in an acrylic holder. The antennal holder was placed inside a humidified condenser and maintained at $5^{\circ} \mathrm{C}$. The output signal from the antenna was amplified by a customized high input impedance DC amplifier and recorded on an HP 3390A integrator.

Chemical Analysis GC-MS was carried out as previously described (Zhang et al., 1999; Nojima et al., 2003a,b; Cha et al., 2008) with a Shimadzu GCMS-QP5050A quadrupole mass spectrometer in EI (at $70 \mathrm{eV}$ ) scan mode coupled with a Shimadzu GC-17A equipped with a nonpolar DB-1 ms capillary column or a polar EC-Wax Econo-Cap capillary column. Helium was the carrier gas $(54 \mathrm{kPa}$ at $1.1 \mathrm{ml} / \mathrm{min})$. GC conditions and temperature program were as for the GC-EAD analyses. The interface temperature was set at $260^{\circ} \mathrm{C}$. Volatile compounds were identified by comparison of chromatographic retention times and mass spectra with those of authentic standards analyzed on the same instru- ment. The identification was further verified by antennal responses in the GC-EAD analyses to the standard compounds. Quantification of the relative ratio of the compounds that elicited EAD responses was made from the adsorbent collection based on total ion abundances from GC/MS analyses. As we did not add an internal standard to adsorbent samples for behavioral testing purposes, standard solutions containing $0.1,1,10$, and $100 \mathrm{ng}$ of the each compound that elicited EAD responses in $1 \mu$ l of methylene chloride were prepared and analyzed to obtain calibration curves.

Chemicals The compounds pentyl hexanoate, hexyl butanoate, butyl hexanoate, propyl hexanoate, pentyl butanoate, butyl butanoate, 1-octen-3-ol, 3-methylbutan-1-ol, 3methylbutyl acetate, dimethyl trisulfide, $\beta$-caryophyllene (purities $>98 \%$ ), and dihydro- $\beta$-ionone ( $>90 \%$ ) were purchased from Sigma-Aldrich (St. Louis, MO, USA). Butyl acetate $(>99 \%)$ and pentyl acetate $(>98 \%)$ were purchased from TCI America (Portland, OR, USA), and ethyl acetate (99.9\%) was purchased from Fischer Scientific (Pittsburgh, PA, USA). The compound (3E)-4,8-dimethyl-1,3,7-nonatriene (DMNT) was synthesized by oxidation of geraniol and then by Wittig reaction with methylenetriphenylphosphorane (Greenwald et al., 1963) and purified (>97\% with $>$ $97 \% E$-isomer by $\mathrm{GC} / \mathrm{MS}$ ) using flash chromatography on silica gel. The synthesis product was eluted with hexane and then subjected to Kugelrohr distillation.

Synthetic Blends and Flight Tunnel Sources We prepared synthetic blends for western, eastern, and hybrid mayhaw based on the EAD active volatile compounds identified from GC-EAD and GC-MS analyses (Fig. 2). The synthetic blends for apple, downy hawthorn, and flowering dogwood were based on Zhang et al. (1999) and Nojima et al. (2003a, b). Table 2 shows the proportion of each compound in the respective blends. The western mayhaw, eastern mayhaw, hybrid mayhaw, and apple blends were prepared such that the concentration of the total volatile mixture was $1 \mu \mathrm{g} / \mu \mathrm{l}$ in hexane. Downy hawthorn and flowering dogwood blends were prepared as described in Nojima et al. (2003a,b). As in our previous flight tunnel studies, we applied $200 \mu \mathrm{l}$ of a synthetic blend to a red rubber septum (hexane-washed; Thomas Scientific, Swedesboro, NJ, Cat. No. $1780 \mathrm{~J} 07)$ as the corresponding doses elicited maximal levels of upwind flight (Zhang et al., 1999; Linn et al., 2003; Nojima et al., 2003a,b). The septum sources were prepared $60 \mathrm{~min}$ prior to a test and were clipped onto the bottom of a $7.5 \mathrm{~cm}$ red plastic sphere (Gempler's Inc., Mt. Horeb, WI, USA). Fresh sources and red spheres were used for each replicate. For adsorbent extracts, we adjusted (either by diluting with hexane or concentrated under a gentle stream of nitrogen gas) the concentration (GC peak 
size) of GC-EAD active volatiles to match the GC profiles of the synthetic blend at $1 \mu \mathrm{g} / \mu \mathrm{l}$ concentration, and applied $200 \mu \mathrm{l}$ of the extract to a rubber septum.

Modified Synthetic Blends Based on the similar high response levels of flies to whole fruit adsorbent extracts and synthetic blends (see next section below), we prepared three modified blends by adding and/or subtracting compounds from the complete blends, to determine the relative importance of individual volatiles in the blend, or those that might function as inter-specific behavioral antagonists (Table 3). Because of the limited availability of flies, we concentrated our effort on the compounds butyl acetate, found in the eastern mayhaw blend but not in the western blend, and 3-methylbutan-1-ol, previously demonstrated to be an essential volatile for the upwind flight response of northern downy hawthorn flies (Linn et al., 2005b) and functioning as a behavioral antagonist for apple-origin flies. Blend W1 represented the complete 6-component western blend (Wc) with butyl acetate added. Blends E1 and E2 represented the complete 8-component eastern blend (Ec) with butyl acetate removed, and with both butyl acetate and 3-methylbutan-1-ol removed, respectively. The modified blends were prepared so that each compound was always in the same amount as in the corresponding complete blends, thus eliminating the potential effect of variation in concentration. For flight tunnel testing, we applied $200 \mu \mathrm{l}$ of the modified blends to a rubber septum. The concentration of each modified blend is listed in Table 3.

Flight Tunnel The response of flies to host fruit volatiles was measured in a sustained-flight tunnel (Nojima et al., 2003a). Flight-tunnel conditions were $23-24^{\circ} \mathrm{C}$, $50-70 \%$ r.h., $35 \mathrm{~cm} / \mathrm{s}$ wind speed, 1500 lux light intensity. Sexually mature adult flies (males and females) 10-21-d-old post-eclosion that had never been previously exposed to the fruit volatile blends (i.e., fruit odor-naïve flies) were tested during the $3^{\text {rd }}$ to $11^{\text {th }} \mathrm{h}$ of the $16 \mathrm{~h}$ photophase period in the flight tunnel. Flies were selected from holding cages located in a separate, environmentally controlled room, placed singly in glass vials, taken to the room housing the flight-tunnel, and then allowed to acclimate for at least $30 \mathrm{~min}$ before testing. Individual flies were transferred to a screen holding cage, which was then placed on a release stand such that the open end of the cage faced upwind at a distance of $1 \mathrm{~m}$ to the odor source. Flies were given $1 \mathrm{~min}$ to respond, and scored by a human observer for the following behaviors: 1 ) remain in release cage $=$ fly did not take flight, but remained in the release cage, generally walking and grooming; 2) taking flight $=$ flight from the release cage to the sides, top or floor of the tunnel; and 3) upwind-directed flight $=$ fly faced upwind, walked to the edge of the release cage (100 $\mathrm{cm}$ from source), took flight and initiated upwind oriented flight in the odor plume. An upwind flight response was scored as positive if the fly exhibited plume-oriented flight for at least $50 \mathrm{~cm}$ toward the sphere [we previously showed that at this distance flies are not attracted to the red sphere alone with no odor source (Linn et al., 2003)]. In some cases, flies made complete flights to the red sphere, but mostly their upwind oriented flights ended within $20-25 \mathrm{~cm}$ of the sphere with the fly landing on the floor or side walls of the tunnel. We suspect this was due to negative visual effects of the red sphere at close range. Large red spheres simulate an apple fruit, or cluster of dogwood and red hawthorn (C. mollis) fruit, but may not be an optimal visual stimulus for mayhaw flies. The red sphere was retained in the present study to provide a consistent assay environment between the current experiments and previous studies (Linn et al., 2003). Also, in the following sections, reference to 'agonist' volatiles refers to those that contributed to the positive upwind directed flight response to a particular blend, and 'antagonist' refers to a non-natal host volatile that, when added to a blend resulted in a significant reduction in upwind directed flights. The effect of the antagonist was characterized by flies exhibiting arrested flight within $25 \mathrm{~cm}$ of the release cage, hovering (1-2 s) in the plume, followed by cross-wind casting, then turning and flying in a downwind direction and landing on the floor or side walls of the tunnel. These behaviors were strikingly similar to the pattern observed for behavioral antagonists in moth sex pheromone blends (Linn and Roelofs, 1995; Cardé and Haynes, 2004).

For each of the host plants, our experimental protocol involved first testing adsorbent extracts in the flight tunnel, with the expectation that response levels should be high, indicating that the behaviorally active blend was contained in the extract, and that no potential deterrent compounds were present, such as might occur with over-ripe or rotting fruit. Given a high response level to the extract, we then tested the candidate synthetic blends that were selected from the GC-EAD profiles based on the consistency of the responses over the majority $(>75 \%)$ of the profiles. Again, the expectation was that response levels should be high and equivalent to those observed with the extracts. We then tested flies to modified blends that had volatiles subtracted or added to the complete blends to determine whether all of the compounds identified from the GC-EAD profiles were required for maximal response (upwind directed flight). For each extract or synthetic blend, different sets of flies were

Fig. 2 Simultaneous recorded GC-EAD responses of mayhaw-origin fly antennae to corresponding adsorbent collections. Different traces indicate antennal response of a western mayhaw-origin flies to western adsorbent samples, b eastern mayhaw-origin flies to eastern adsorbent samples, and $\mathbf{c}$ western mayhaw-origin flies to "hybrid" adsorbent samples 


\section{(a) Western mayhaw}

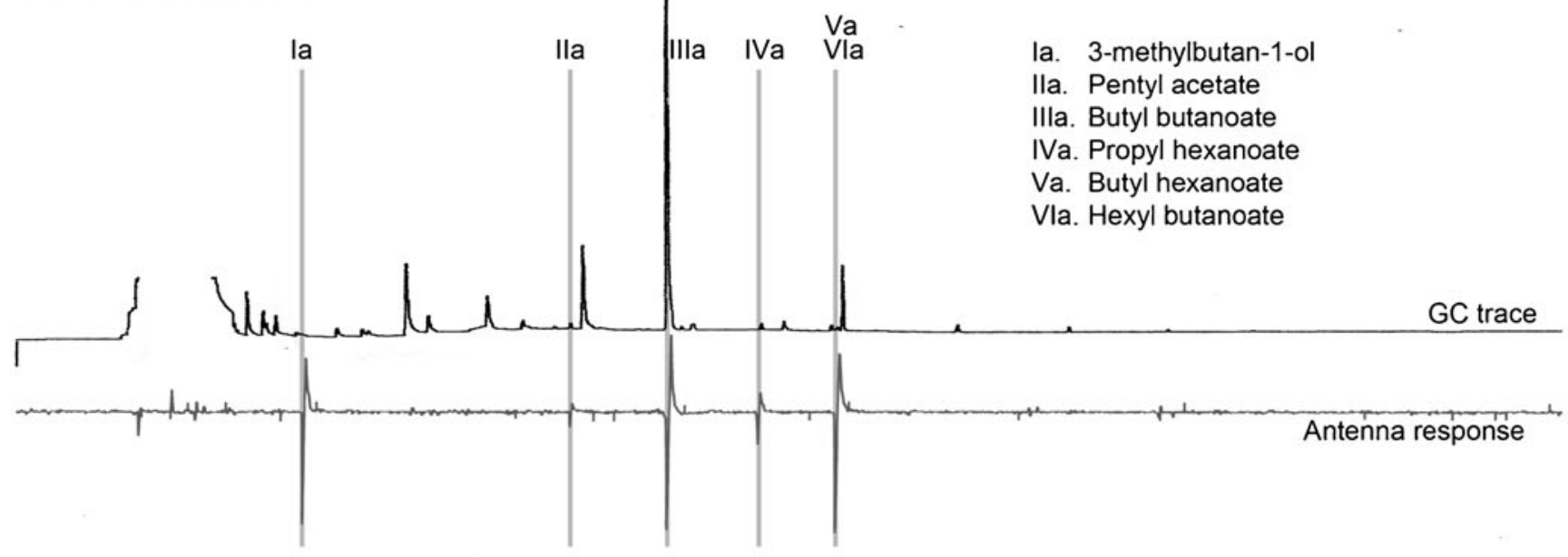

(b) Eastern mayhaw

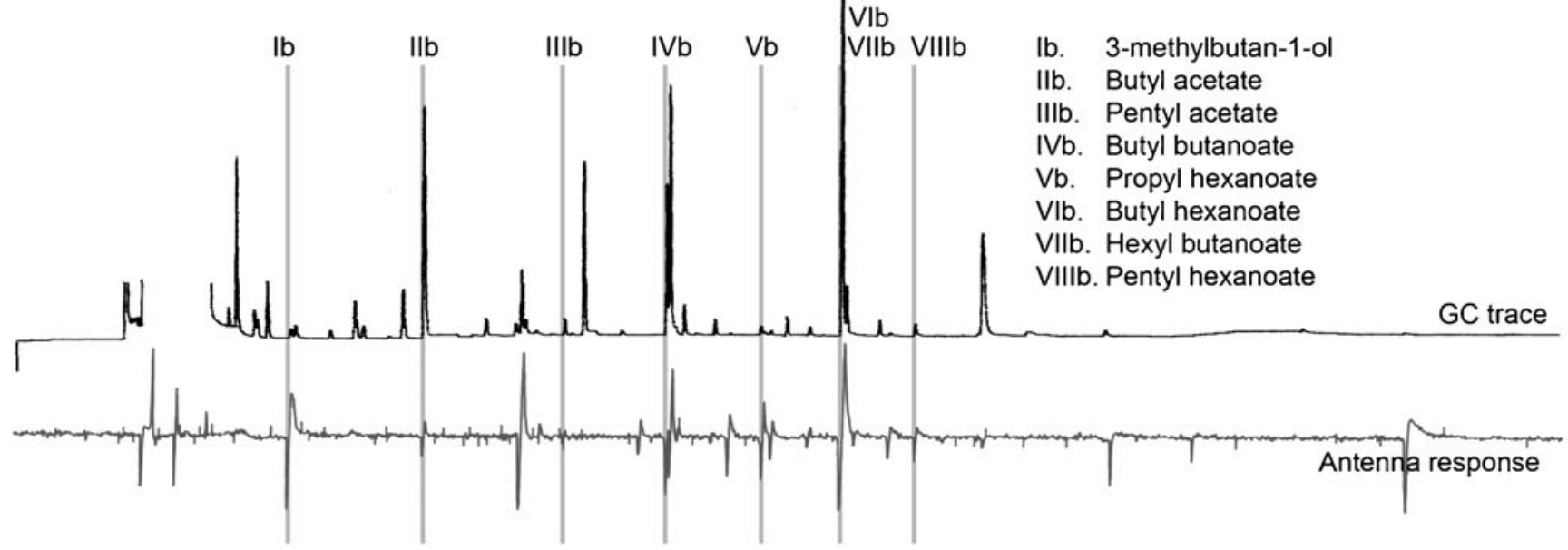

(c) Hybrid mayhaw

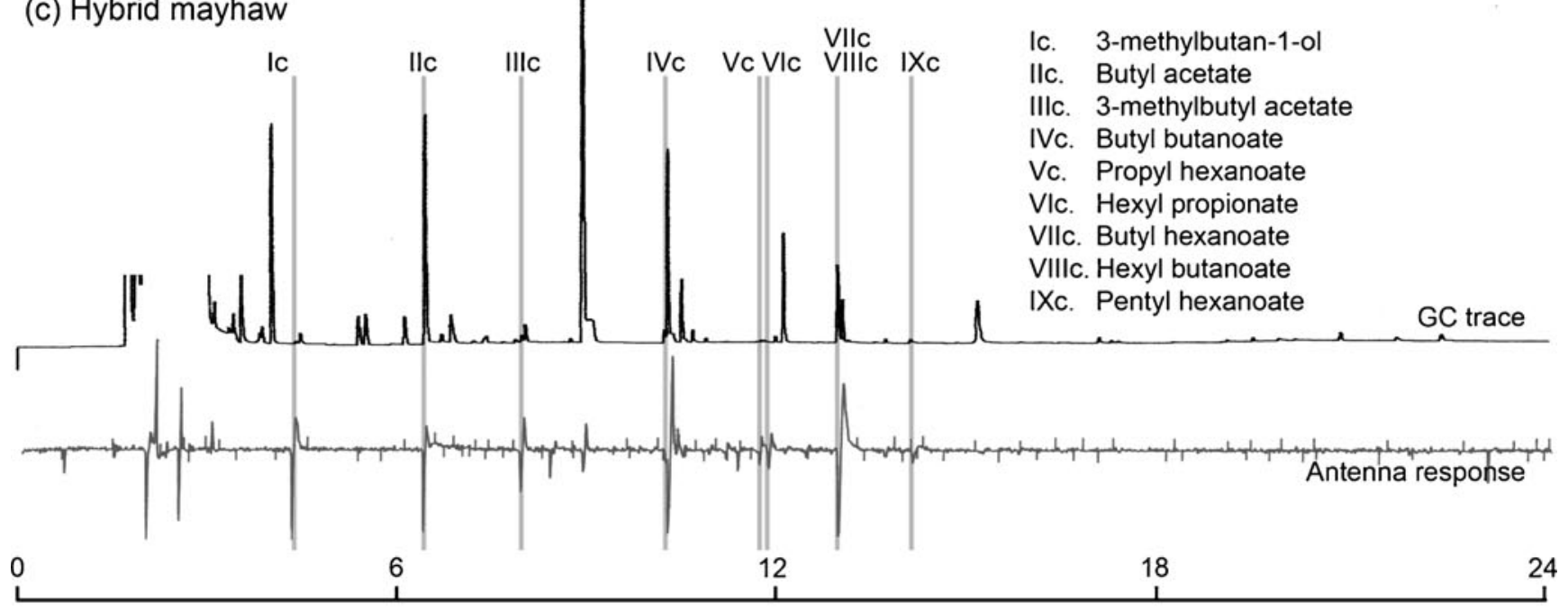

Retention Time (minute) 
Table 2 The relative ratios (\%) of volatile compounds in different synthetic blends. Ratios for three mayhaw blends were based on GC/MS analyses of volatile adsorbent samples collected from 3 different mayhaw species. Ratios for apple, downy hawthorn and dogwood are those for the synthetic blends previously developed by Zhang et al. (1999) and Nojima et al. (2003a, b). DMNT indicates (3E)-4,8-dimethyl-1,3,7-nonatriene

\begin{tabular}{|c|c|c|c|c|c|c|}
\hline \multirow{2}{*}{ Chemicals } & \multicolumn{6}{|c|}{ Synthetic blends (\%) } \\
\hline & $\begin{array}{l}\text { Western } \\
\text { mayhaw (Wc) }\end{array}$ & $\begin{array}{l}\text { Eastern } \\
\text { mayhaw (Ec) }\end{array}$ & $\begin{array}{l}\text { "Hybrid" } \\
\text { mayhaw (Hc) }\end{array}$ & Apple & $\begin{array}{l}\text { Downy } \\
\text { Hawthorn }\end{array}$ & $\begin{array}{l}\text { Flowering } \\
\text { Dogwood }\end{array}$ \\
\hline 3-methylbutan-1-ol & 44 & 2 & 1 & & 4 & 27.5 \\
\hline Butyl acetate & & 47 & 57 & & & \\
\hline Pentyl acetate & 6 & 2 & & & & \\
\hline Butyl butanoate & 6 & 12 & 5 & 10 & & \\
\hline Propyl hexanoate & 6 & 1 & 1 & 4 & & \\
\hline Butyl hexanoate & 26 & 25 & 23 & 37 & 0.01 & \\
\hline Hexyl butanoate & 12 & 9 & 6 & 44 & & \\
\hline Pentyl hexanoate & & 2 & 3 & 5 & & \\
\hline 3-methylbutyl acetate & & & 3 & & 1.5 & 0.9 \\
\hline Hexyl propionate & & & 1 & & & \\
\hline Ethyl acetate & & & & & 94.3 & 54.9 \\
\hline DMNT & & & & & 0.07 & \\
\hline Dihydro- $\beta$-ionone & & & & & 0.1 & \\
\hline Dimethyl trisulfide & & & & & & 1.9 \\
\hline 1-octen-3-ol & & & & & & 9.1 \\
\hline$\beta$-caryophyllene & & & & & & 5.8 \\
\hline
\end{tabular}

tested as the flies became available from field collections of infested fruit. For each set of experiments, almost all of the flies were tested to all of the treatments, usually over a continuous period of 2-4 d, with no more than 3 treatments being tested on a given day. In previous studies, we have

Table 3 Relative ratio (\%) of volatile compounds in the complete western mayhaw (Wc) and eastern mayhaw (Ec) synthetic blends and their modified blends (W1, E1, and E2). We prepared the modified blends so that the same compound was always in the same amount as in corresponding complete blends, thus eliminating the potential effect of variation in concentration. For flight tunnel tests, $200 \mu \mathrm{l}$ of Wc or Ec shown that $R$. pomonella flies can be repeatedly tested without affecting odor preference as displayed in the flight tunnel (Dambroski et al., 2005). Differences in the frequency of upwind flight were compared using Fisher's Exact Test in $\mathrm{R}$ ( $\mathrm{R}$ development core team, Vienna, Austria).

(prepared at $1.0 \mu \mathrm{g} / \mu \mathrm{l}$ ), thus $200 \mu \mathrm{g}$ of total volatile compounds, were loaded onto a rubber septum. The ratio and concentration of modified blends (W1, E1, and E2) were formulated as found in Wc or Ec. For flight tunnel tests of the modified blends, we also loaded $200 \mu \mathrm{l}$ of W1, E1, or E2 to a rubber septum. Bold characters indicate the modified compounds

\begin{tabular}{|c|c|c|c|c|c|}
\hline \multirow[t]{2}{*}{ Chemicals } & \multicolumn{5}{|c|}{ Synthetic blends (\%) } \\
\hline & $\begin{array}{l}\text { Western } \\
\text { mayhaw (Wc) }\end{array}$ & $\begin{array}{l}\text { Modified Western } \\
\text { mayhaw (W1) }\end{array}$ & $\begin{array}{l}\text { Eastern } \\
\text { mayhaw (Ec) }\end{array}$ & $\begin{array}{l}\text { Modified Eastern } \\
\text { mayhaw (E1) }\end{array}$ & $\begin{array}{l}\text { Modified Eastern } \\
\text { mayhaw (E2) }\end{array}$ \\
\hline 3-methylbutan-1-ol & 44 & 44 & 2 & 2 & \\
\hline Butyl acetate & & 47 & 47 & & \\
\hline Pentyl acetate & 6 & 6 & 2 & 2 & 2 \\
\hline Butyl butanoate & 6 & 6 & 12 & 12 & 12 \\
\hline Propyl hexanoate & 6 & 6 & 1 & 1 & 1 \\
\hline Butyl hexanoate & 26 & 26 & 25 & 25 & 25 \\
\hline Hexyl butanoate & 12 & 12 & 9 & 9 & 9 \\
\hline Pentyl hexanoate & & & 2 & 2 & 2 \\
\hline Total $\%$ & 100 & 147 & 100 & 53 & 51 \\
\hline Concentration $(\mu \mathrm{g} / \mu \mathrm{l})$ & 1.0 & 1.47 & 1.0 & 0.53 & 0.51 \\
\hline
\end{tabular}




\section{Results}

Identification of Volatiles from Western, Eastern, and C. rufula Mayhaw Fruit Mayhaw fruit was analyzed using SPME and adsorbent extracts with GC-EAD and GC-MS. Figure 2 a-c shows GC-EAD recordings from the antennae of a fly from each mayhaw-origin population exposed to the whole fruit extract at a stage when $>90 \%$ of the fruit was ripe. We note that whereas the traces indicate the presence of some unidentified peaks with EAD responses, these responses were not present in the majority $(>75 \%)$ of GC-EAD runs examined. The relative ratio of compounds that elicited EAD responses from flies in each geographic location estimated with GC-MS are listed in Table 2.

For western mayhaw (C. opaca), fruit was analyzed from two samples collected in 2007 (Idlewild, East Feliciana Parish, LA, USA, and Polk Co., TX, USA). A total of 12 different antennal pairs of 9 female and 3 male flies (1-10 replicate runs/pair) were used for the GC-EAD analysis. All of the flies were of western mayhaw-origin from Dewey Wills, LaSalle Parrish, LA, USA. Compounds that consistently elicited EAD responses were identified as (Ia) 3-methylbutan-1-ol, (IIa) pentyl acetate, (IIIa) butyl butanoate, (IVa) propyl hexanoate, (Va) butyl hexanoate, and (VIa) hexyl butanoate. Two adsorbent extracts of volatiles from whole mayhaw fruit from each location that were made for quantitative analysis of key volatiles (GC-MS) and flight tunnel analysis were identical.

For eastern mayhaw (C. aestivalis), fruit collected in 2007 from Byron, GA, USA and in 2010 from Crisp Co., GA, USA, was analyzed. A total of 7 different antennal pairs of 5 female and 2 male flies (all from Byron; 1-10 replicate runs/ pair) were used for the GC-EAD analysis. The corresponding compounds that consistently generated EAD responses from tested flies were identified as (Ib) 3-methylbutan-1-ol, (IIb) butyl acetate, (IIIb) pentyl acetate, (IVb) butyl butanoate, (Vb) propyl hexanoate, (VIb), butyl hexanoate, (VIIb) hexyl butanoate, and (VIIIb) pentyl hexanoate.

Fruit from the potential hybrid mayhaw, C. rufula, was analyzed from a 2010 collection made at Parker Lake, MS, USA. A total of 7 different antennal pairs of 5 female and 2 male eastern mayhaw-origin flies (1-10 replicate runs/pair) from Byron, GA, USA, were used for the GC-EAD analysis. The corresponding compounds that consistently generated EAD responses from tested flies were identified as (Ic) 3-methylbutan-1-ol, (IIc) butyl acetate, (IIIc) 3-methylbutyl acetate (IVc) butyl butanoate, (Vc) propyl hexanoate, (VIc) hexyl propionate, (VIIc) butyl hexanoate, (VIIIc) hexyl butanoate, and (IXc) pentyl hexanoate.

Behavioral Responses of Mayhaw-Origin Flies to Natal Adsorbent Extracts and Non-natal Northern Volatile Blends Western and eastern-origin flies were tested first in the flight tunnel to western, eastern, and $C$. rufula adsorbent extracts and to the previously developed apple, northern downy hawthorn (DH), and flowering dogwood (DW) blends (Fig. 3). A total of 30 western flies from $C$. opaca fruit collected from La Salle Parish, $(N=17)$ and Grant Parish $(N=13), \mathrm{LA}$, USA, were tested to the western (W-MH) and eastern mayhaw (E-MH) adsorbent extracts, and 13 of the western mayhaw flies from La Salle Parish also were tested to the extract of the hybrid (H-MH) (Fig. 3a). A higher proportion of western flies displayed upwind flight to the western extract $(67 \%)$ than to the eastern extract $(10 \%$; $P<0.001,1 d f)$, hybrid extract $(0 \% ; P<0.001,1 d f)$, apple blend $(3 \% ; P<0.001,1 d f)$, northern downy hawthorn blend $(30 \% ; P=0.009,1 d f)$, and flowering dogwood blend $(0 \% ; P<0.001,1 d f)$.

For eastern mayhaw, a total of 27 flies from $C$. aestivalis fruit collected from Byron, GA, USA, were tested (Fig. 3b).
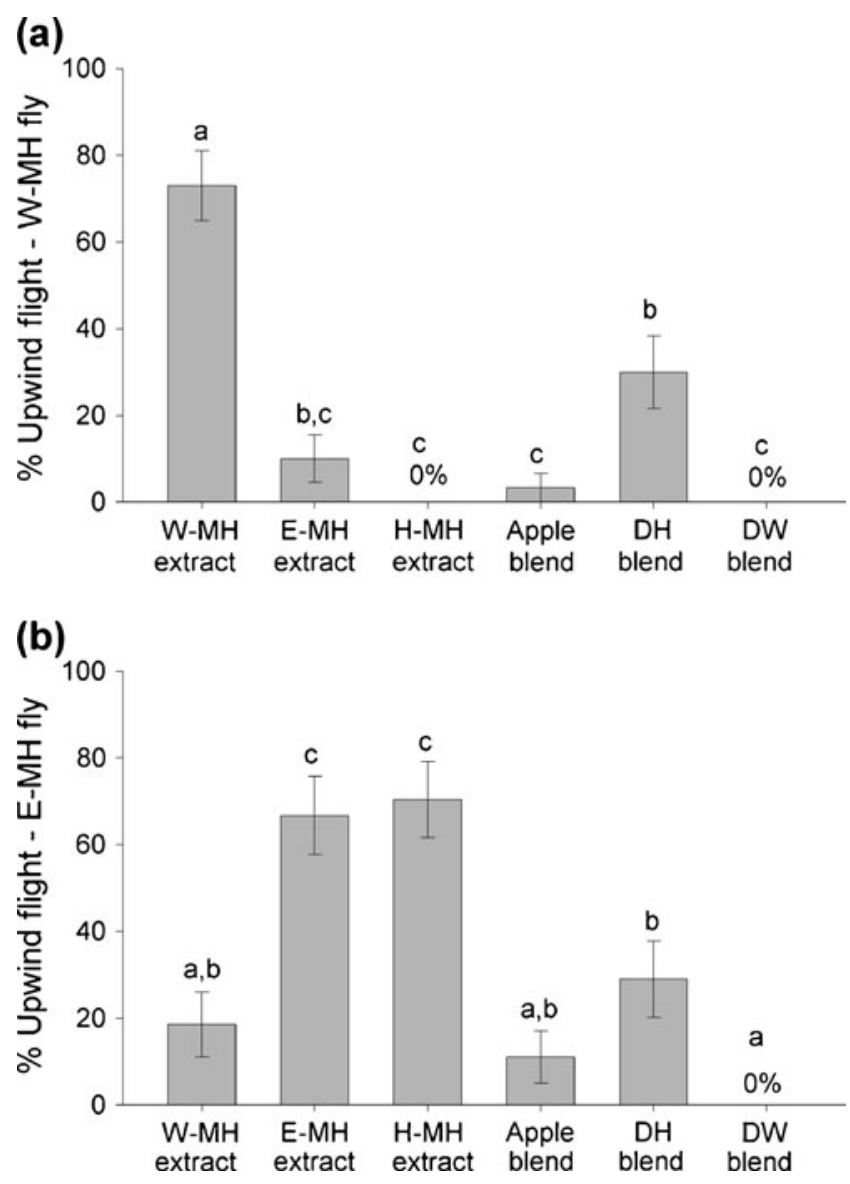

Fig. 3 Upwind flight responses $(\% \pm 1 S E)$ of a western mayhaw-origin flies and $\mathbf{b}$ eastern mayhaw-origin flies to western, eastern and hybrid mayhaw whole fruit adsorbent extracts and previously developed volatile blends for 3 northern host plants: apple, downy hawthorn, and flowering dogwood. List of abbreviations used and what they stand for: W-MH, western mayhaw; E-MH, eastern mayhaw; H-MH, hybrid mayhaw; DH, downy hawthorn; DW, flowering dogwood. Different letters on bars indicate significant differences $(P<0.05)$ 
As was the case for western flies, a higher proportion of eastern flies exhibited upwind flight to the eastern extract (63\%) compared to the western extract $(19 \% ; P=0.002,1$ $d f)$, the apple blend $(11 \% ; P<0.001,1 d f)$, and the flowering dogwood blend $(0 \% ; P<0.001,1 d f)$. The difference between levels of upwind flight of eastern flies to their natal extract and the downy hawthorn blend was marginally significant (63 vs. $30 \% ; P=0.055,1 d f$ ). However, eastern mayhaw flies did not differ significantly in levels of upwind flight between their natal eastern extract vs. the hybrid $C$. rufula extract (63 vs. $70 \%$, respectively; $P=0.610,1 d f)$.

Behavioral Responses of Mayhaw Flies to Synthetic Mayhaw Blends Eastern and western mayhaw flies next were tested to synthetic blends of the complete set of GCEAD active volatiles identified for western (designated $\mathrm{Wc}$ ) and eastern mayhaw (designated Ec) (Table 2). The proportion of western flies displaying upwind flight to the 6-component Wc blend was 75\% (Fig. 4a) and not significantly different from the $67 \%$ value exhibited by western flies to the $C$. opaca extract $(P=0.814,1 d f)$. Similarly, the proportion of eastern flies displaying upwind flight to the 8-component Ec blend was 74\% (Fig. 4b), a level equivalent to and not significantly different from the $63 \%$ value exhibited by eastern flies to the $C$. aestivalis extract $(P=0.419,1 d f)$. These two results support the hypothesis that the $\mathrm{Wc}$ and Ec blends contain all of the key volatiles found in the extracts that elicit maximal response levels for western and eastern fly behavior, respectively. However, western and eastern flies displayed significantly reduced levels of upwind flight to their respective non-natal blends. The response level for western flies to the eastern Ec blend was $8 \%$ upwind flight (Fig. 4a), while the response level for eastern flies to the western $\mathrm{Wc}$ blend was $12 \%$ upwind flight (Fig. 4b).

We also tested eastern and western mayhaw-origin flies to a 9-component $C$. rufula hybrid blend (designated Hc) (Fig. 4a and b). The results were similar to those observed for the $C$. rufula adsorbent extract. Once again, western flies showed a low level of response to the Hc blend ( $8 \%$ upwind flight), while eastern flies responded in high proportion to the $\mathrm{Hc}$ blend ( $60 \%$ upwind flight).

Behavioral Responses of Mayhaw Flies to Modified Blends To better determine the impact of potential key volatile compounds responsible for the agonist and antagonist behavioral responses of mayhaw flies to natal and non-natal fruit volatiles, we tested three different modified blends with a focus on 3-methylbutan-1-ol and butyl acetate (Table 3). A total of 62 western mayhaw-origin flies (La Salle Parish, LA, USA, $N=27$; Grant Parish, LA, USA, $N=17$; Nacagdoches Co., TX, USA, $N=18$ ) were
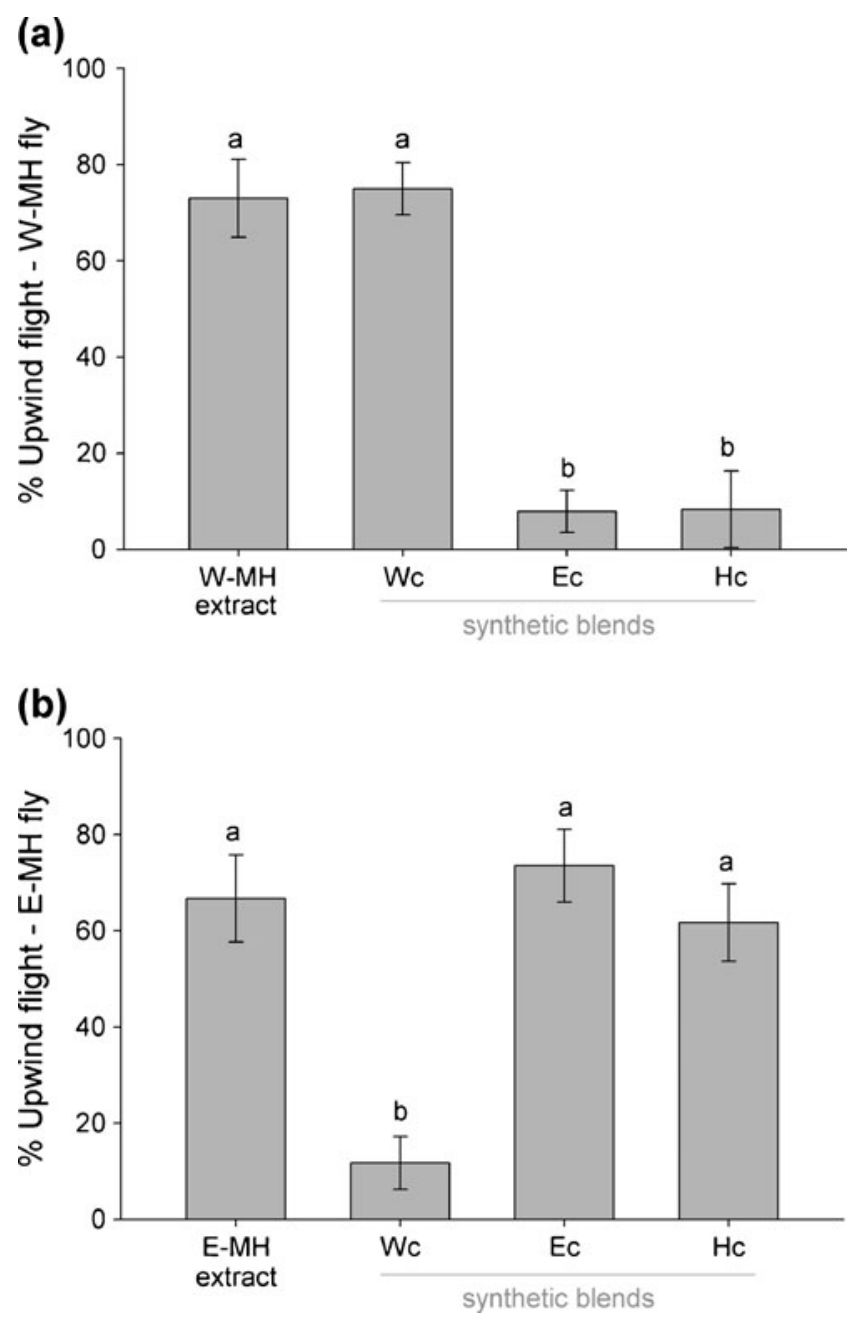

Fig. 4 Upwind flight responses $(\% \pm 1 S E)$ of a western mayhaworigin flies and $\mathbf{b}$ eastern mayhaw-origin flies to their natal whole fruit adsorbent extract and volatile blends of western (Wc), eastern (Ec), and "hybrid" mayhaw (Hc). W-MH and E-MH stand for western mayhaw and eastern mayhaw, respectively. Different letters on bars indicate significant differences $(P<0.05)$

tested to the modified mayhaw blends (Fig. 5). Western flies displayed reduced levels of upwind flight to the W1 (Wc plus butyl acetate) blend (10 vs. 75\% upwind flight, respectively; $P<0.001,1 d f$ ), indicating that butyl acetate functions as an inter-specific behavioral antagonist on western fly behavior. Consistent with this hypothesis, western fly response to the eastern blend E1 (Ec minus butyl acetate) was not statistically different from that to the complete Wc blend ( 68 vs. $75 \% ; P=0.647,1 d f$ ). The critical importance of 3-methylbutan-1-ol was evidenced by the fact that no western flies exhibited upwind-directed flight to the modified E2 blend (E1 minus 3-methylbutan1-ol). The tests with the modified blends also suggested that the compound pentyl hexanoate did not greatly affect flight behavior of western flies. Although pentyl hexanoate, like butyl acetate, is present in the eastern, but not western, 


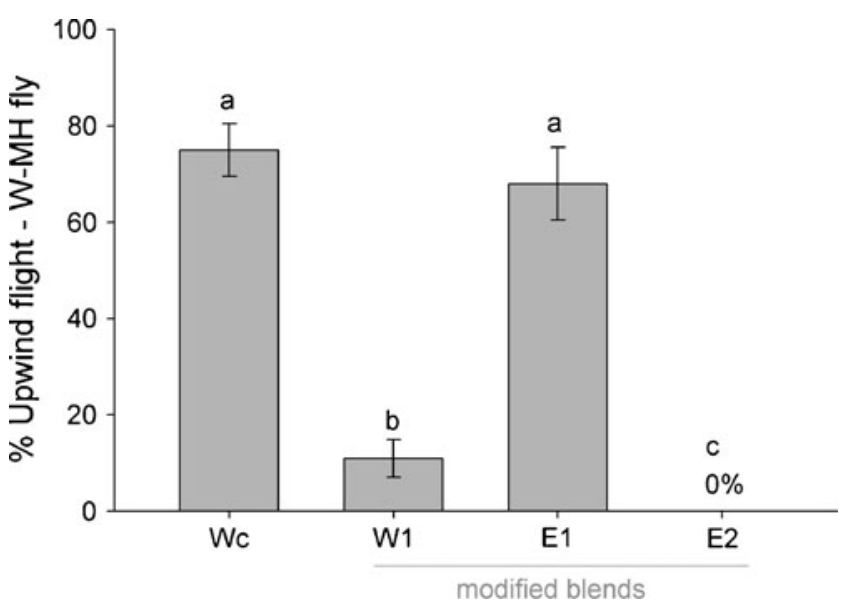

Fig. 5 Upwind flight responses $(\% \pm 1 S E)$ of western mayhaw-origin flies to the complete western volatile blend (Wc), modified blend W1 (Wc plus butyl acetate), E1 (complete eastern mayhaw blend minus butyl acetate), and E2 (E1 minus 3-methylbutan-1-ol). W-MH stands for western mayhaw. Different letters on bars indicate significant differences $(P<0.05)$

blend (Table 3), western flies responded in high proportions $(68 \%)$ to the modified eastern blend E1 that had butyl acetate removed, but still contained pentyl hexanoate.

A total of 34 eastern flies from Byron, GA, USA, were tested to the E1 and E2 blends (Fig. 6). Eastern flies exhibited a reduced level of upwind-directed flight to the E1 (Ec minus butyl acetate) blend (7\% upwind flight) compared to the complete 8-component Ec blend (74\% upwind flight; $P<0.001,1 d f$ ), suggesting that butyl acetate is a critical volatile for maximal response by eastern flies. Eastern flies showed no response $(0 \%$ upwind-directed flights) to the E2 blend that lacked both butyl acetate and 3-methylbutan-1-ol.

\section{Discussion}

We developed synthetic volatile blends of western $(C$. opaca) and eastern (C. aestivalis) mayhaw fruit using GCEAD and GC-MS analysis of SPME and whole fruit adsorbent collections. Western and eastern flies displayed high levels of upwind directed flight to their respective natal blends and a reduced response to almost all of the non-natal blends in flight tunnel assays, the lone exception being eastern mayhaw flies acceptance of the hybrid $C$. rufula blend. A key difference between the eastern and western blends is the presence of butyl acetate in the eastern blend. Addition or subtraction of butyl acetate to the synthetic blends demonstrated the critical importance of this volatile for stimulating upwind directional flight in eastern flies and for antagonizing (arresting) the upwind flight of western flies. This sharp contrast in preference behavior indicates that $R$. pomonella flies infesting western and eastern fruit differ in their host odor response phenotypes. The results for butyl acetate also can help to explain the behavioral responses of mayhaw flies to the fruit volatiles of the morphologically intermediate $C$. rufula, which may represent a hybrid between $C$. opaca and C. aestivalis in the state of Mississippi. We found that C. rufula, like the eastern mayhaw, $C$. aestivalis, contains butyl acetate in high levels. As a consequence, eastern flies tested against the $C$. rufula blend showed a similar level of upwind flight compared to their natal blend, while the upwind flight of western flies was antagonized by the hybrid blend (Fig. 4a and b). The apparent lack of $R$. pomonella infestation of $C$. rufula in Mississippi may thus be due to inadequate sampling of host fruit or some other abiotic or biotic factor such as dramatic year-to-year variability in the timing or amount of fruit set, and/or high interspecific competition, as the fruit of C. rufula would appear to present no olfactory barrier to colonization by eastern mayhaw flies.

A principal motivation for the current study was to investigate a potential role for southern mayhaw flies in the formation of the apple host race in the northern USA. In particular, it has been hypothesized that the introduction of a geographically differentiated, hawthorn-infesting form of $R$. pomonella from the South could be the source of the apple-infesting race in the North (Carson, 1989; although see Bush et al., 1989). This would imply that in the southern USA, a "pre-adapted" hawthorn-infesting population of $R$. pomonella exists that preferentially orients to apple fruit volatiles and is antagonized by downy hawthorn (C. mollis) fruit volatiles. However, in the current study, flies collected from both eastern and western fruit exhibited low response levels with the apple blend in flight tunnel assays (6 and 10\% upwind flight, respectively). Indeed, the proportion of upwind flight exhibited by southern mayhaw

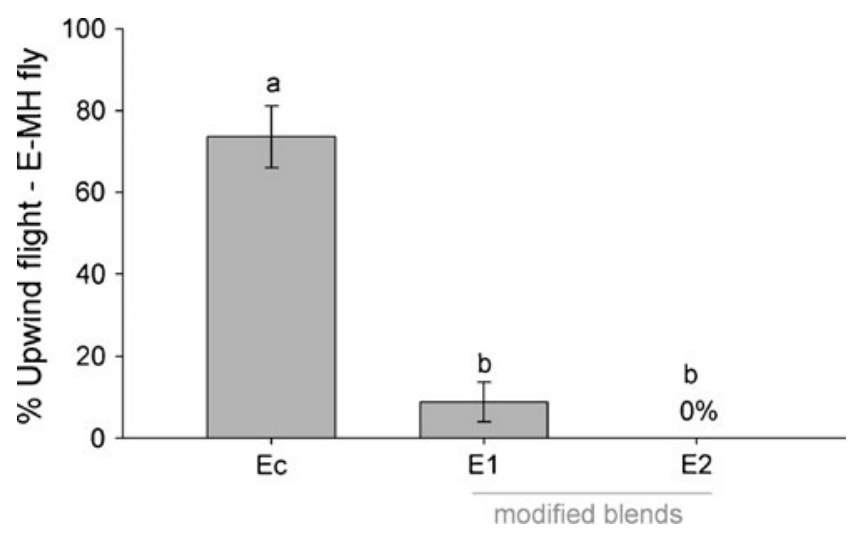

Fig. 6 Upwind flight responses $(\% \pm 1 S E)$ of eastern mayhaw-origin flies to the complete eastern mayhaw blend (Ec), E1 (Ec minus butyl acetate), and E2 (E1 minus 3-methylbutan-1-ol). E-MH stands for eastern mayhaw. Different letters on bars indicate significant differences $(P<0.05)$ 
flies to the apple blend was lower than that shown for the northern downy hawthorn blend (Fig. 3). Further, all of these apple-responding flies also responded to their natal fruit extract or synthetic blend, indicating that they are examples of broadly responsive flies, ones that do not exhibit a high degree of response specificity for blend quality. Mayhaw infesting populations from the South, therefore, do not preferentially orient to apple and are not "pre-adapted", direct precursors to the apple race in the North. However, western and eastern mayhaw blends from the South do contain certain compounds present in the apple blend and absent in northern downy hawthorn blend (Table 2). In particular, both mayhaw blends and the apple blend contain butyl butanoate, propyl hexanoate, and hexyl butanoate, and eastern mayhaw and apple further share pentyl hexanoate. Mayhaw flies are thus capable of detecting certain components of the apple blend, and some southern flies are capable of responding to both hawthorn and apple blends, supporting the hypothesis that odor response phenotypes in the South may have contributed to pre-standing variation in northern hawthorn populations facilitating a rapid, sympatric shift to apple. Perhaps most importantly, northern downy hawthorn and both mayhaw blends share 3-methybutan-1-ol in common. 3-Methybutan1 -ol is not present in the apple blend (Table 2), and is an antagonist of upwind flight by apple-origin flies when added to the apple blend (Linn et al., 2005a). The lack of response of both eastern and western flies to modified blends lacking 3-methylbutan-1-ol, together with our previous findings for northern downy hawthorn flies (Linn et al., 2003; 2005a), supports the hypothesis that this compound functions as a critical volatile for hawthorn fly host discrimination.

Rather than a direct shift of southern mayhaw flies to apple to form the northern apple fly race, our current results instead provide evidence for the possible existence of differentiated host races (or even sibling species) of hawthorn-infesting $R$. pomonella in the South. Neither western nor eastern flies were attracted greatly to the northern downy hawthorn blend or to their respective non-natal mayhaw blend. These findings are consistent with differences in olfactory preference and discrimination of volatile mixtures contributing to prezygotic reproductive isolation between these populations if they were to come in geographic contact. In an accompanying study (Cha et al., 2011, this issue), we report fruit volatile and fly response differences for two additional hawthorn species in the South (the blueberry hawthorn, $C$. brachyacantha, and the green hawthorn, $C$. viridis), further supporting the hypothesis of southern hawthorn-infesting races of $R$. pomonella.

We now have developed active volatile blends for six different host fruit of $R$. pomonella group flies. Previously, we optimized volatile blends for apple (Zhang et al., 1999), northern downy hawthorn (Nojima et al., 2003a), and flowering dogwood (Nojima et al., 2003b). The addition of the three new western, eastern, and hybrid mayhaw blends in the current study will allow us to further characterize phenotypic patterns and elucidate the genetic architecture of host plant preference in the model $R$. pomonella system, thus leading to a greater understanding of the role that host volatile recognition plays in phytophagous insect speciation. Studies that compare the behavior of southern mayhaw flies to those of other southern Crataegus infesting populations will give us insight into the generality of host odor recognition as an isolating mechanism in the $R$. pomonella species complex and into the nature of fitness trade-offs posed by blends composed of overlapping components (Cha et al., 2011, this issue). Additionally, the importance of pre-standing variation in hawthorn flies to recognize certain specific fruit volatiles in apple may become clearer as we form a complete picture of host race formation among southern $R$. pomonella populations.

Acknowledgments We thank Tracy Arcella, Stewart Berlocher, Scot Egan, Andrew Forbes, Glen Hood, Dave Costello, H. W. Jackson, Jim Stevens, and Sheina Sim for help in collecting fruit and fly samples, thoughtful discussion, and/or assistance in helping prepare the manuscript for publication. We also thank Callie Musto, Kathy Poole, and Paula Fox for maintaining the flies received from Notre Dame, and Harvey Reissig, Cynthia Smith, and Dave Combs for use of the Geneva, New York, apple maggot colony. We also thank Aijun Zhang for the synthesis of (3E)-4,8-dimethyl-1,3,7-nonatriene. The research was supported by grants to J.L.F. and C.L. from the National Science Foundation and to J.L.F. from the USDA.

\section{References}

Berlocher, S. H. and ENQUist, M. 1993. Distribution and host plants of the apple maggot fly, Rhagoletis pomonella (Diptera: Tephritidae) in Texas. J. Kans. Entomol. Soc. 66:51-59.

Berlocher, S. H. and FedER, J. L. 2002. Sympatric speciation in phytophagous insects: Moving beyond controversy? Annu. Rev. Entomol. 47: 773-815.

Berlocher, S. H., McPheron, B. A., Feder, J. L., and Bush, G. L. 1993. A revised phylogeny of the Rhagoletis pomonella (Diptera: Tephritidae) sibling species group. Ann. Ent. Soc. Amer. 86:716-727.

Bush, G. L. 1966. The Taxonomy, Cytology, and Evolution of the genus Rhagoletis in North America (Diptera: Tephritidae). Museum of Comparative Zoology, Cambridge, MA.

BuSH, G. L. 1969. Sympatric host race formation and speciation in frugivorous flies of genus Rhagoletis (Diptera: Tephritidae). Evolution 23: 237-251.

Bush, G. L., Feder, J. L., Berlocher, S. H., Mcpheron, B. A., SMith, D. C., and ChILCOTE, C. A. 1989. Sympatric origins of $R$. pomonella. Nature 339: 346.

CARDÉ, R. T. and HAYNeS, K. F. 2004. Structure of the pheromone communication channel in moths, pp. 283-332, in R. T. Cardé and J. G. Millar (eds). Advances in Insect Chemical Ecology. Cambridge University Press, Cambridge, UK.

Carson, H. L. 1989. Sympatric pest. Nature 338: 304.

Cha, D. H., Nojima, S., Helser, S. P., Zhang, A., LinN, C. E. JR., RoElofs, W. L., and LoEB, G. M. 2008. Identification and field 
evaluation of grape shoot volatiles attractive to female grape berry moth (Paralobesia viteana). J. Chem. Ecol. 34:1180-1189.

ChA, D. H., Powell, T. H. Q., Feder, J. L., AND LinN, C. E. JR. 2011. Identification of host fruit volatiles from green hawthorn (Crataegus viridis) and blueberry hawthorn (C. brachyacantha) host plants attractive to different phenotypes of Rhagoletis pomonella flies in the southern United States. J. Chem. Ecol. 37: this issue.

CoYNe, J. A. and OrR, H. A., 2004. Speciation. Sinauer Associates, Sunderland, MA.

Dambroski, H. R., Linn, C. E. JR., Feder, J. L., Berlocher, S. H., NoJima, S., and RoElofs, W. L. 2005. The genetics of fruit odor discrimination in Rhagoletis pomonella flies and its implications for sympatric host race formation and speciation. Evolution 59: 19531964.

DAmbroski, H. R. and Feder, J. L. 2007. Host plant and latituderelated diapause variation in Rhagoletis pomonella: a test for multifaceted life history adaptation on different stages of diapause development. J. Evol. Biol. 20: 2101-2112.

Feder, J. L., Chilcote, C. A., and Bush, G. L. 1988. Genetic differentiation between sympatric host races of the apple maggot fly Rhagoletis pomonella. Nature 336: 61-64.

Feder, J. L., Hunt, T. A., and Bush, G. L. 1993. The effects of climate, host plant phenology, and host fidelity on the genetics of apple and hawthorn infesting races of Rhagoletis pomonella. Entomol. Exp. Appl. 69: 117-135.

Feder, J. L., Opp, S. B., Wlazlo, B., Reynolds, K., Go, W., and SPISAK, S. 1994. Host fidelity is an effective premating barrier between sympatric races of the apple maggot fly. Proc. Natl. Acad. Sci. USA 91: 7990-7994.

FEDER, J. L. 1998. The apple maggot fly, Rhagoletis pomonella: Flies in the face of conventional wisdom? pp. 130-144, in D. J. Howard, and S. H. Berlocher, (eds.). Endless Forms: Species and Speciation. Oxford University Press, Oxford.

FeIN, B. L., ReIssig, W. H., and RoElofs, W. L. 1982. Identification of apple volatiles attractive to the apple maggot. J. Chem. Ecol. 8: $1473-1487$.

FilchaK, K. E., Roethele, J. B., and Feder, J. L. 2000. Natural selection and sympatric divergence in the apple maggot Rhagoletis pomonella. Nature 407: 739-742.

Forbes, A. A., FISHER, J., and FEDER, J. L. 2005. Habitat avoidance: Overlooking an important aspect of host-specific mating and sympatric speciation? Evolution 59: 1552-1559.

FunK, D. J., FILChaK, K. E., and FedER, J. L. 2002. Herbivorous insects: model systems for the comparative study of speciation ecology. Genetics 116: 251-267.

GreEnWALD, R., ChaYKovsky, M., and COREY, E.J. 1963. The Wittig reaction using methylsulfinyl carbanion-dimethyl sulfoxide. $J$ Org. Chem. 28:1128-1129.

LINN, C. E. JR. and RoELOFS, W. L. 1995. Pheromone communication in the moths and its role in the speciation process. pp. 263-300 in D. H. Lambert and H. Spencer (eds.). Speciation and the Recognition Concept: Theory and Application. Johns Hopkins University Press, Baltimore.
Linn, C. E. JR., Feder, J. L., NoJima, S., Dambroski, H. R., Berlocher, S. H., and Roelofs, W. 2003. Fruit odor discrimination and sympatric host race formation in Rhagoletis. Proc. Natl. Acad. Sci. USA 100: 11490-11493.

LinN, C. E. JR., DAmbroski, H. R., Feder, J. L., Berlocher, S. H., NoJima, S., and Roelofs, W. L. 2004. Postzygotic isolating factor in sympatric speciation in Rhagoletis flies: reduced response of hybrids to parental host-fruit odors. Proc. Natl. Acad. Sci. USA. 101: 17753-17758.

LinN, C. E. JR., NoJIMA, S., and Roelofs, W. L. 2005a. Antagonist effects of non-host fruit volatiles on discrimination of host fruit by Rhagoletis flies infesting apple (Malus pumila), hawthorn (Crataegus spp.), and flowering dogwood (Cornus florida). Entomol. Exp. Appl. 114: 97-105.

LinN, C. E. JR., DAMBroski, H., NOJIMA, S., FedER, J. L., BERLOCHER, S. H., and RoELOFS, W. L. 2005b. Variability in response specificity of apple, hawthorn, and flowering dogwood-infesting Rhagoletis flies to host fruit volatile blends: implications for sympatric host shifts. Entomol. Exp. Appl. 116: 55-64.

Mcpheron, B. A., Smith, D. C., and Berlocher, S. H. 1988. Genetic differences between host races of Rhagoletis pomonella. Nature. 336: 64-66.

Michel, A. P., Sim, S., Powell, T. H. Q., Taylor, M. S., Nosil P., and FEDER, J. L. 2010. Widespread genomic divergence during sympatric speciation. Proc. Natl. Acad. Sci. USA 107: 9724-9.

NeILSON, W. T. A. 1965. Culturing of apple maggot Rhagoletis pomonella. J. Econ. Entomol. 58: 1056.

NoJIMA, S., LinN, C. E., JR., ZhANG, A., Morris, B., and RoElofs, W. L. 2003a. Identification of host fruit volatiles from hawthorn (Crataegus spp.) attractive to hawthorn-origin Rhagoletis pomonella flies. J. Chem. Ecol. 29: 319-334.

NoJima, S., LinN, C. E., JR., Zhang, A., Morris, B., and Roelofs, W. L. 2003b. Identification of host fruit volatiles from flowering dogwood (Cornus florida) attractive to dogwood-origin Rhagoletis pomonella flies. J. Chem. Ecol. 29: 2347-2357.

Prokopy, R. J., BenNetT, E. W., and Bush, G. L. 1971. Mating behavior in Rhagoletis pomonella (Diptera: Tephritidae). I. Site of assembly. Can. Entomol. 103: 1405-1409.

Prokopy, R. J., BenNetT, E. W., and Bush, G. L. 1972. Mating behavior in Rhagoletis pomonella (Diptera: Tephritidae). II. Temporal organization. Can. Entomol. 104: 97-104.

ReISsig, W. H. and SMITH, D. C. 1978. Bionomics of Rhagoletis pomonella (Diptera: Tephritidae) in Crataegus. Ann. Entomol. Soc. Am. 71: 155-159.

SARGENt, C. S. 1933. Manual of the Trees of North America. Houghton Mifflin Co. Boston, MA

Smadja, C., and Butlin, R. K. 2009. On the scent of speciation: the chemosensory system and its role in premating isolation. Heredity 102: 77-97.

Zhang, A., Linn, C. E. Jr., Wright, S., Prokopy, R., Reissig, W., and RoELOFS, W. L. 1999. Identification of a new blend of apple volatiles attractive to the apple maggot, Rhagoletis pomonella. J. Chem. Ecol. 25: 1221-1232. 